\title{
Bacteriological profile of diabetic foot ulcer using hicrome UTI Agar
}

\author{
Kala Yadhav M.L ${ }^{1}$, Chetana G S ${ }^{2}$ \\ ${ }^{1}$ Dr. Kala Yadhav M L, Professor ${ }^{2}$ Dr. Chetana G S, Postgraduate, both authors are affiliated with Department of \\ Microbiology, Bangalore Medical College and Research Institute, Karnataka, India.
}

Address for Correspondence: Dr. Chetana G.S, Postgraduate in Department of Microbiology, Bangalore Medical College and Research Institute, Email- g.s_chetana@yahoo.com.

\begin{abstract}
Introduction: Foot ulcers are one of the common complications of diabetes mellitus. Diabetic foot ulcer infections are usually polymicrobial infections. For effective treatment, quick isolation and identification of causative organisms with appropriate antibiotic susceptibility testing is needed. Objective: Isolation and identification of bacteria using routine media and HiCrome UTI agar. Materials and Methods: Samples were taken from all Type II diabetes mellitus patients with foot ulcers attending hospital. Samples were collected from deeper portion of the ulcer using 2 sterile swabs and processed using conventional methods and HiCrome UTI agar. Antibiotic susceptibility testing was done on Mueller Hinton agar according to CLSI guidelines. Results: Among 100 samples tested, 138 organisms were isolated as 38\% of samples yielded mixed growth. Conventional methods failed to detect 6 (4.3\%) isolates form mixed cultures. HiCrome UTI agar isolated all organisms in the cultures including 4 isolates of enterococci and 2 isolates of MSSA, which were missed in conventional methods $(\mathrm{p}<0.01)$. Pseudomonas $(22.4 \%)$ was commonest organism isolated. Followed by Klebsiella spp. (18.8\%), Proteus spp. (15.2\%), MSSA (13\%), Escherichia coli (11.5\%), Citrobacter spp. (7.2\%), MRSA (7.2\%), Enterococcus spp. (4.3\%). Conclusion: Gram negative organisms (75.3\%) were predominantly isolated in the study. HiCrome UTI agar can be used for primary identification and quick isolation of organisms where facilities for routine culturing are not available. It is both sensitive and specific in isolating and identifying organisms as in polymicrobial infections.
\end{abstract}

Keywords: Diabetic foot ulcer, HiCrome UTI agar, Polymicrobial infections, Antibiotic susceptibility.

\section{Introduction}

The Indian diabetic population is expected to increase to 57 million by the year 2025 [1]. Diabetic foot ulcer is a global concern and one of the most feared complications of diabetes. Infected foot wounds are a common problem in people with diabetes and constitute the most frequent diabetes-related cause of hospitalization. Infection sometimes leads to amputation of the infected foot if not treated promptly [2]. The impaired micro-vascular circulation in patients and high blood glucose levels in uncontrolled diabetes favors the development of infection in foot wounds [3]. The local injuries, inappropriate foot wear and improper foot care further compromise the blood supply in the lower extremities. The wound infection is superficial to begin with, but with delay in treatment it can spread to subcutaneous tissue, muscles and bones leading to

Manuscript received: $30^{\text {th }}$ May 2017

Reviewed: $9^{\text {th }}$ June 2017

Author Corrected: $18^{\text {th }}$ June 2017

Accepted for Publication: 26 ${ }^{\text {th }}$ June 2017 complications like cellulitis and gangrene [4]. Many of these infections polymicrobial in nature and are colonized with antimicrobial-resistant organisms, including methicillin-resistant Staphylococcus aureus (MRSA) and extended spectrum beta-lactamase producing gram negative organisms (ESBL) which makes it difficult to treat.

While the foot infections in persons with diabetes are initially treated empirically, a therapy which is directed at the known causative organisms will improve the outcome. For effective management and to prevent complications there is a need for appropriate antibiotic therapy, along with regular glycemic control, wound care, surgical debridement [5]. So there is need for proper management of diabetic foot ulcer requires early detection of causative bacteria and selection of appropriate antibiotics based on the culture and the antimicrobial testing. 
This study was aimed at determining the bacterial profile of infected diabetic foot ulcers and the antibiotic resistance pattern of the bacterial isolates. HiCrome UTI agar (chromogenic agar) mainly used in identification of urinary pathogens and not many studies are done using other samples [6]. We tried using HiCrome UTI agar for quick isolation and identification of bacteria from polymicrobial infection of diabetic ulcers.

\section{Materials and Methods}

Study design: This is a cross sectional comparative study involving diabetic patients with foot ulcer

Study period: From July 2016 to December 2016

Place of study: Bangalore Medical College And Research Institute, ethical clearance was obtained.

Inclusion criteria: Patients of age 18 years and above with Type II diabetes and clinically suspected of having microbial infection in their foot ulcer with Wagner's grade 1 and above.

Exclusion criteria: Patients less than 18 years of age, gestational diabetes, Type I diabetes and grading of Wagner's grade 0 were excluded from the study.

Sample size: A total of 100 patients were selected and samples were collected and processed for bacteriological investigations.

Sample collection and processing: The clinical history of the patients such as age, sex, type of diabetes, duration of diabetes, size of ulcer and duration of ulcer were recorded on a proforma. The patients were clinically examined and ulcers were graded according to the Wagner's grade. The samples were collected after obtaining informed consents from the patients.

Two sterile swabs were used to collect sample from deeper portions of the ulcer. Gram stain was also performed using one swab and the other was used for culture. Swabs were processed by direct inoculation onto HiCrome UTI agar and conventional media.

They were incubated aerobically at $37^{\circ} \mathrm{C}$ overnight or maximum of 24 hours and the plates were examined for growth. The organisms were identified on the basis of their Gram staining properties, biochemical reactions and color on HiCrome UTI agar.
Colony morphology on HiCrome UTI agar is as follows:

Pseudomonas aeruginosa- pale green translucent colonies

Klebsiella spp.- dark blue colonies

Proteus spp.- yellowish brown, transparent colonies

E coli- pink translucent colonies

Citrobacter spp.- magenta colored colonies

Staphylococcus spp.- tiny, creamy white, convex colonies.

Enterococcus spp.- dark blue green, very tiny colonies [7].

Antimicrobial susceptibility will be done by means of agar disc diffusion method of Kirby Bauer according to the guidelines of clinical and laboratory standards institute [8].

ESBL production was confirmed by using discs of Ceftazidime $(30 \mu \mathrm{g})$ and Ceftazidime Clavulanic acid $(30 / 10 \mu \mathrm{g})$ respectively. The test organism was inoculated as a lawn on a Mueller Hinton agar plate and the above mentioned discs were placed on the plate. The plates were incubated at $37^{\circ} \mathrm{C}$ overnight and they were examined next day. An increase in the zone diameter, which was equal to or more than $5 \mathrm{~mm}$ for the antimicrobial agent which was tested in combination with Clavulanic acid, in comparison to the antimicrobial which was tested alone, indicated that the strain was an ESBL producer.

The phenotypic test for the detection of MRSA was done by using a cefoxitin $(30 \mu \mathrm{g})$ disc. A zone of inhibition which was equal to or more than $22 \mathrm{~mm}$ was considered as susceptible to Cefoxitin and the organism was reported as Methicillin Sensitive Staphylococcus aureus (MSSA). Those isolates which produced a zone of inhibition which was less than or equal to $21 \mathrm{~mm}$ were considered as Methicillin Resistant Staphy lococcus aureus (MRSA).

Statistical analysis: The data obtained is in the form of frequencies and percentages and is analyzed using statistical software; $p$ values were calculated and projected in form of tables and pie charts. 


\section{Results}

A total of 100 patients with type two diabetes mellitus were studied, which included 69 males and 31 females, ratio being 2.22:1. The age of the patients ranged from 35 to 80 years. The mean age was found to be 56.8 years.

The maximum numbers of patients $(32 \%)$ were in the age group of 51 to 60 years. The next most prevalent age group was between 61 and 70 years $(26 \%)$.

All the 100 samples processed were positive for culture, of which 38(38\%) samples showed polymicrobial infection. Among the 138 isolates, gram positive organism constituted $34(24.6 \%)$ isolates and the gram negative constituted 104 $(75.3 \%)$ isolates.

Conventional methods isolated 132 organisms, while HiCrome UTI agar isolated and identified all the 138 organisms including enterococci and MSSA from mixed cultures for which $\mathrm{p}$ value was found to be $<0.01$. HiCrome UTI agar allowed presumptive identification of organisms and isolated colonies without the need for subculture.

Conventional methods failed to isolate 4 enterococci and 2 MSSA isolates from mixed cultures i.e. $4.3 \%$ of total isolates were missed.

Pseudomonas was commonest organism isolated (22.4\%), followed by Klebsiella sp. (18.8\%), Proteus sp. (15.2\%), MSSA (13\%), Escherichia coli (11.5\%), Citrobacter sp. (7.2\%), MRSA (7.2\%), Enterococci (4.3\%).

Most of Gram negative bacilli were resistant to Aztreonam, Cefepime, Ciprofloxacin and showed sensitivity to Imipenem, Piperacillin/ tazobactam, Colistin and Polymyxin B and as shown in table- 1.

$28.7 \%$ of enterobacteriaceae were found to be ESBL producers.

Majority of gram positive cocci showed sensitivity to Clindamycin, Linezolid and resistance to Penicillin and erythromycin as shown in table-2. $35.7 \%$ of staphylococci were found to be methicillin resistant.

Table-1: Antibiotic sensitivity pattern of Gram Negative Bacilli ( $\%$ of sensitivity).

\begin{tabular}{|c|c|c|c|c|c|c|c|c|c|c|c|}
\hline $\begin{array}{c}\text { Name and no } \\
\text { of isolates }\end{array}$ & AMC & - & CPM & $\mathbf{C}$ & AT & IMP & CIP & COT & CAZ & CL & PB \\
\hline $\begin{array}{c}\text { Pseudomonas } \\
\text { aeruginosa } \\
\mathbf{n = 3 1}\end{array}$ & & $\begin{array}{c}25 \\
(80.6)\end{array}$ & $\begin{array}{c}15 \\
(48.3)\end{array}$ & - & $\begin{array}{c}18 \\
(58)\end{array}$ & $\begin{array}{c}27 \\
(87)\end{array}$ & $\begin{array}{c}20 \\
(64.5)\end{array}$ & - & $\begin{array}{c}23 \\
(74.1)\end{array}$ & $\begin{array}{c}31 \\
(100)\end{array}$ & $\begin{array}{c}31 \\
(100)\end{array}$ \\
\hline $\begin{array}{l}\text { Klebsiella } \\
\text { spp. } n=26\end{array}$ & $\begin{array}{c}15 \\
(57.6)\end{array}$ & $\begin{array}{c}25 \\
(96.1)\end{array}$ & $\begin{array}{c}11 \\
(42.3)\end{array}$ & $\begin{array}{c}20 \\
(76.9)\end{array}$ & $\begin{array}{c}14 \\
(53.8)\end{array}$ & $\begin{array}{c}24 \\
(92.3)\end{array}$ & $\begin{array}{c}18 \\
(69.2)\end{array}$ & $\begin{array}{c}16 \\
(61.5)\end{array}$ & $\begin{array}{c}14 \\
(53.8)\end{array}$ & - & - \\
\hline $\begin{array}{c}\text { Proteus spp. } \\
n=21\end{array}$ & $\begin{array}{c}17 \\
(80.9)\end{array}$ & $\begin{array}{c}21 \\
(100)\end{array}$ & $\begin{array}{c}12 \\
(57.1)\end{array}$ & $\begin{array}{c}17 \\
(80.9)\end{array}$ & $\begin{array}{c}16 \\
(76.1)\end{array}$ & $\begin{array}{c}21 \\
(100)\end{array}$ & $\begin{array}{c}19 \\
(90.4)\end{array}$ & $\begin{array}{c}18 \\
(85.7)\end{array}$ & $\begin{array}{c}17 \\
(80.9)\end{array}$ & - & - \\
\hline $\begin{array}{c}\text { E coli } \\
n=16\end{array}$ & $\begin{array}{c}11 \\
(68.7)\end{array}$ & $\begin{array}{c}15 \\
(93.7)\end{array}$ & $\begin{array}{c}7 \\
(43.7)\end{array}$ & $\begin{array}{c}12 \\
(75)\end{array}$ & $\begin{array}{c}9 \\
(56.2)\end{array}$ & $\begin{array}{c}14 \\
(87.5)\end{array}$ & $\begin{array}{c}8 \\
(50)\end{array}$ & $\begin{array}{c}7 \\
(43.7)\end{array}$ & $\begin{array}{c}8 \\
(50)\end{array}$ & - & - \\
\hline $\begin{array}{l}\text { Citrobacter } \\
\text { spp. } n=10\end{array}$ & $\begin{array}{c}6 \\
(60)\end{array}$ & $\begin{array}{c}9 \\
(90)\end{array}$ & $\begin{array}{c}5 \\
(50)\end{array}$ & $\begin{array}{c}8 \\
(80)\end{array}$ & $\begin{array}{c}5 \\
(50)\end{array}$ & $\begin{array}{c}10 \\
(100)\end{array}$ & $\begin{array}{c}6 \\
(60)\end{array}$ & $\begin{array}{c}7 \\
(70)\end{array}$ & $\begin{array}{c}5 \\
(50)\end{array}$ & - & - \\
\hline \multicolumn{12}{|c|}{$\begin{array}{l}\text { Amoxicillin-clavulanate acid[AMC] }(20 / 10 \mu \mathrm{g}) \text {, Piperacillin/tazobactam[PIT] (100/10 } \mu \mathrm{g}) \text {, Cefepime[CPM] } \\
(30 \mu \mathrm{g}) \text {, Chloramphenicol[C] }(30 \mu \mathrm{g}) \text {, Aztreonam[AT] }(30 \mu \mathrm{g}) \text {, Imipenem[IMP] }(10 \mu \mathrm{g}) \text {, Ciprofloxacin[CIP] }(5 \mu \mathrm{g}) \\
\text { and Trimethoprim- sulfamethoxazole[COT] }(1.25 / 23.75 \mathrm{~g}) \text {, Ceftazidime[CAZ] }(30 \mu \mathrm{g}) \text {, Polymyxin B[PB] }(300 \\
\text { units) and Colistin[CL] }(10 \mu \mathrm{g})\end{array}$} \\
\hline
\end{tabular}


Table-2: Antibiotic sensitivity pattern of the Gram positive cocci ( $\%$ of sensitivity)

\begin{tabular}{|c|c|c|c|c|c|c|c|c|c|c|c|}
\hline $\begin{array}{c}\text { Name and no } \\
\text { of isolates }\end{array}$ & $\overline{\mathbf{P}}$ & $\mathbf{C X}$ & AK & GEN & $\mathbf{E}$ & DO & CIP & \begin{tabular}{l|l} 
CD \\
\end{tabular} & $\mathrm{C}$ & VA & $\mathbf{L Z}$ \\
\hline $\begin{array}{c}\text { MSSA } \\
n=18\end{array}$ & $\begin{array}{c}0 \\
(0)\end{array}$ & $\begin{array}{c}18 \\
(100)\end{array}$ & $\begin{array}{c}16 \\
(88.8)\end{array}$ & $\begin{array}{c}16 \\
(88.8)\end{array}$ & $\begin{array}{c}9 \\
(50)\end{array}$ & $\begin{array}{c}15 \\
(83.3)\end{array}$ & $\begin{array}{c}13 \\
(72.2)\end{array}$ & $\begin{array}{c}16 \\
(88.8)\end{array}$ & $\begin{array}{c}11 \\
(61.1)\end{array}$ & - & $\begin{array}{c}18 \\
(100)\end{array}$ \\
\hline $\begin{array}{c}\text { MRSA } \\
n=10\end{array}$ & $\begin{array}{c}0 \\
(0)\end{array}$ & $\begin{array}{c}0 \\
(0)\end{array}$ & $\begin{array}{c}7 \\
(70)\end{array}$ & $\begin{array}{c}8 \\
(80)\end{array}$ & $\begin{array}{c}6 \\
(60)\end{array}$ & $\begin{array}{c}8 \\
(80)\end{array}$ & $\begin{array}{c}7 \\
(70)\end{array}$ & $\begin{array}{c}8 \\
(80)\end{array}$ & $\begin{array}{c}6 \\
(60)\end{array}$ & - & $\begin{array}{c}10 \\
(100)\end{array}$ \\
\hline $\begin{array}{c}\begin{array}{c}\text { Enterococci } \\
\mathrm{n}=6\end{array} \\
\end{array}$ & $\begin{array}{c}3 \\
(50) \\
\end{array}$ & - & - & - & $\begin{array}{c}4 \\
(66.6) \\
\end{array}$ & $\begin{array}{c}6 \\
(100) \\
\end{array}$ & $\begin{array}{c}4 \\
(66.6) \\
\end{array}$ & - & $\begin{array}{c}5 \\
(83.3) \\
\end{array}$ & $\begin{array}{c}6 \\
(100) \\
\end{array}$ & $\begin{array}{c}6 \\
(100) \\
\end{array}$ \\
\hline
\end{tabular}

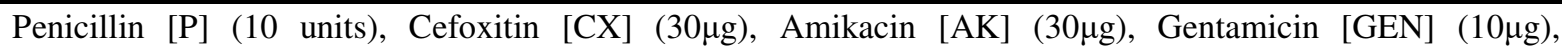
Erythromycin [E] $(15 \mu \mathrm{g})$, Doxycycline [DO] $(30 \mu \mathrm{g})$, Ciprofloxacin [CIP] $(5 \mu \mathrm{g})$, Clindamycin [CD] $(2 \mu \mathrm{g})$,

Chloramphenicol [C] $(30 \mu \mathrm{g})$, Vancomycin [VA] $(30 \mu \mathrm{g})$ and Linezolid [LZ] $(30 \mu \mathrm{g})$
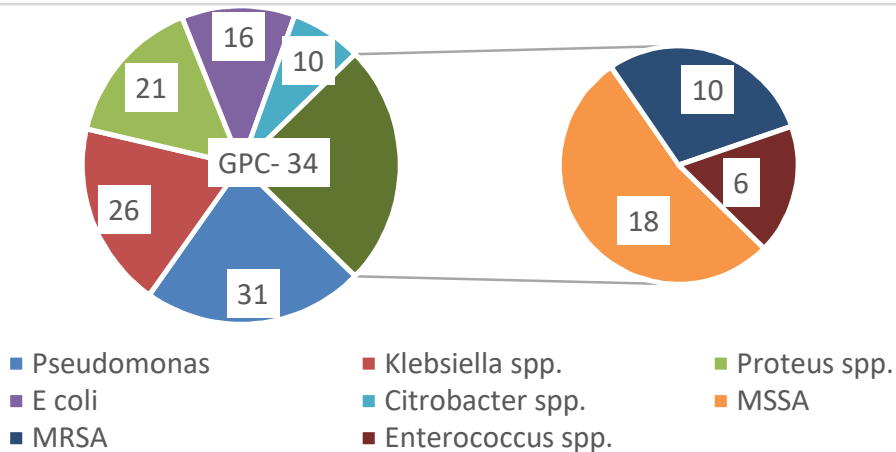

Fig-1: Organisms isolated

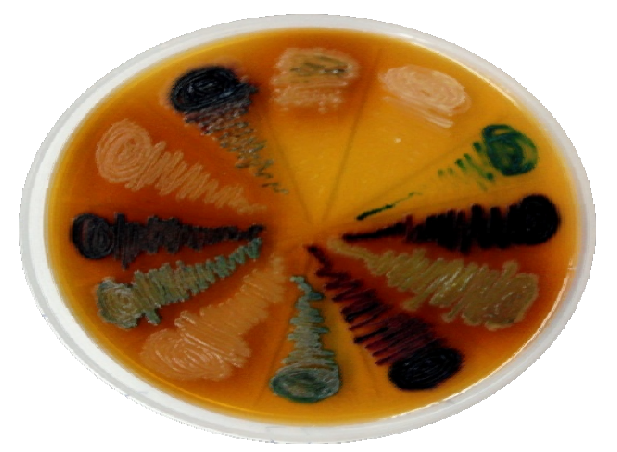

Fig-2: HiCrome UTI agar

\section{Discussion}

Diabetic foot ulcer is one of the most feared complications of diabetes and it is an important cause of the hospitalization among diabetic patients as they are more prone to bacterial infections that spread rapidly, leading to severe complications like cellulitis and gangrene. These infections are usually polymicrobial in nature. Therefore, it is necessary to evaluate the microbial patterns and their antibiotic sensitivities for selection of appropriate antibiotics to decrease morbidity and mortality in the diabetic population.
In our study out of 100 patients, males were more commonly affected than females and male to female ratio being 2.22:1 which is similar to the studies done by Yerat $\mathrm{RC}$ et al, Tiwari $\mathrm{S}$ et al and Dwedar $\mathrm{R}$ et al $[3,9,10]$.

In our study majority of patients presented with diabetic foot ulcers belonged to Wagner grade 2 and 3 whereas in study done by Shanmugam $\mathrm{P}$ et al the maximum number of patients with infected diabetic foot ulcers 
Research Article

belonged to Wagner grade 3 and 4 [1]. In study done by Dwedar $\mathrm{R}$ et al the maximum number of patients with infected diabetic foot ulcers belonged to Wagner grade 2 and $1[10]$.

All the samples yielded growth which means to say that all the diabetic foot ulcers included in our study were infected. In studies done by Shanmugam P et al, Yerat RC et al, Tiwari $\mathrm{S}$ et al and Chaudhry W. N. et al polymicrobial growth was shown to be $50 \%, 56.73 \%$, $43.5 \%$ and $76 \%$ respectively $[1,3,9,11]$. In contrast our study showed $38 \%$ of poly microbial growth.

The number of gram negative bacilli $(75.3 \%)$ isolated were higher compared to the gram positive cocci (24.6\%) depicting a ratio of 3.2:1 which is comparable to Shanmugam $\mathrm{P}$ et al, Mehta VJ et al and Yerat RC et al $[1,2,3]$.

Pseudomonas was the commonest organism isolated in our study which correlates with study done by Mehta VJ et al [2], although MRSA was the predominant isolate in study by Sugandhi P et al [4]. Chaudhry W. $\mathrm{N}$. et al and Patil SV et al showed staphylococcus aureus as most common isolate [11,12]. The studies done by Tiwari $\mathrm{S}$ et al and Dwedar $\mathrm{R}$ et al showed Escherichia coli and Proteus mirabilis as the most common pathogen isolated respectively $[9,10]$.

Our study shows that the isolated bacteria had differential sensitivity patterns against commonly used antibiotics. Most of Gram negative bacilli were resistant to routine antibiotics like Aztreonam, Cefepime, Ciprofloxacin [table-1] and majority of gram positive cocci showed resistance to Penicillin and Erythromycin [table-2] which correlated with most of the studies.

Diabetic foot ulcers are highly prone to colonization with antimicrobial-resistant organisms, including methicillin-resistant Staphylococcus aureus and extended spectrum beta-lactamase producing gram negative organisms. In our study $28.7 \%$ of Eneterobacteriaceae were ESBL producers and 35.7\% of staphylococci were MRSA which is lesser than other studies done by Shanmugam P et al, Mehta VJ et al and Yerat $\mathrm{RC}$ et al $[1,2,3]$. The study done by Dwedar $\mathrm{R}$ et al showed that $49 \%$ of Gram negative bacilli were ESBL producers and $46.8 \%$ of staphylococci were MRSA [10]. In the study done by Chaudhry W. N. et al 66.66, 33.33, 66.7 and 50\% of the Proteus spp., P. aeruginosa, K. pneumoniae and E. coli populations, respectively, were ESBL producers [11].
HiCrome UTI agar was more sensitive in isolating gram positive cocci from mixed cultures when compared to conventional methods.

\section{Conclusion}

Our study showed that the prevalence of Gram-negative infection was higher in diabetic foot ulcers, even though both gram negative bacilli and gram positive cocci cause diabetic foot infections.

HiCrome UTI agar was more accurate when compared to conventional media in isolating enterococci and MSSA from mixed cultures. It reduced the need for subcultures and thus reduced the time taken to give reports. Linezolid and Imipenem were found to be the best drug of the choice against gram positive and gram negative organisms respectively.

Among the combinations antibiotics, Piperacillin / tazobactam was the best drug of choice that can be used for treating diabetic foot infections.

Appropriate usage of antibiotics based on local sensitivity pattern along with surgical debridement and prompt control blood sugar levels help the clinician to treat diabetic foot ulcers effectively which ultimately reduces complications and improves the quality of life of diabetics.

\section{Acknowledgements}

Funding: Nil, Conflict of interest: None initiated, Permission from IRB: Yes

\section{References}

1. Shanmugam P, M J, Susan S L. The bacteriology of diabetic foot ulcers, with a special reference to multidrug resistant strains. J Clin Diagn Res. 2013 Mar; 7 (3): 441-5. doi: 10.7860/JCDR/2013/5091.2794. Epub 2013 Mar 1.

2. Mehta VJ, Kikani KM, Mehta SJ. Microbiological profile of diabetic foot ulcers and its antibiotic susceptibility pattern in a teaching hospital, Gujarat. Int J Basic Clin Pharmacol. (2014), February 15, 2016; 3 (1) : 92-95. DOI: 10.5455/2319-2003.ijbcp.20140209.

3. Yerat RC, Rangasamy VR. A clinicomicrobial study of diabetic foot ulcer infections in South India. Int $\mathbf{J}$ Med Public Health 2015; 5: 236-41. DOI: 10.4103/ 2230-8598. 161545. 
4. Sugandhi P, Prasanth D A. Bacteriological Profile of Diabetic Foot Infections. IJIRSET. 2014; Vol. 3, Issue 7, 14688-14692.

5. Yazdanpanah L, Nasiri M, Adarvishi S. Literature review on the management of diabetic foot ulcer. World J Diabetes. 2015 Feb 15;6(1):37-53. doi: 10.4239/ wjd.v6.i1.37.

6. Jayashri P, Payal R D, Sanjay R, Afroz B, Bimal C, Parul D S. Utility of UTI CHROM agar media for the rapid identification of uropathogens. NHL journal of medical sciences. 2013; Vol 2 (1): 39-42.

7. Zubair M, Malik A, Ahmad J. Diabetic Foot Ulcer: A Review. American Journal of Internal Medicine. Vol. 3, No. 2, 2015, pp. 28-49. DOI: 10.1016/j.dsx. 2015. 04.007.

8. Clinical And Laboratory Standards Institute. Performance Standards For Antimicrobial Susceptibility Testing.M100-S24, Vol 34, no 1, Wayne, Pennsylvania; 2016, p.38-42.
9. Tiwari S, Pratyush D, Dwivedi A, Gupta S, Rai M, Singh S (2012) Microbiological and clinical characteristics of diabetic foot infections in northern India. The Journal Of Infection In Developing Countries 6 (04): 329-332. DOI: https://doi.org/10. 3855 /jidc. 1827.

10. Dwedar R, Ismail D K and Abdulbaky A. Diabetic foot Infection: Microbiological Causes with Special Reference to their Antibiotic Resistance Pattern. Egyptian Journal of Medical Microbiology Volume 24 / No. 3 / July 2015 95-102.

11. Chaudhry W. N., Badar, R., Jamal M., Jeong J., Zafar J., Andleeb S. Clinico-microbiological study and antibiotic resistance profile of mecA and ESBL gene prevalence in patients with diabetic foot infections. Experimental and Therapeutic Medicine 11.3 (2016): 1031-1038. DOI: 10.3892/etm.2016.2996.

12. Patil SV, Mane RR. Bacterial and clinical profile of diabetic foot ulcer using optimal culture techniques. Int J Res Med Sci 2017;5: 496-502. DOI: http://dx.doi.org/10.18203/2320-6012.ijrms20170139.

\section{How to cite this article?}

Kala Yadhav M.L, Chetana G S. Bacteriological profile of diabetic foot ulcer using hicrome UTI Agar. Trop J Path Micro 2017;3(2):195-200.doi: 10.17511/jopm.2017.i2.21. 